\title{
Keratin expression during early embryonic development of Bufo bufo gargarizans
}

\author{
XIE JingwU And HaOJIAN YU \\ Dept. of Biology, Peking University, Beijing 100871, \\ China
}

\begin{abstract}
Three anti-keratin MAbs were used to identify keratins expressed in early embryos of Bufo bufo gargarizans. MAb AF5 recognized three polypeptides of keratin in oocytes, fertilized eggs, up to neurula with $\mathrm{Mr}$ of 68,65 and $60 \mathrm{Kd}$ respectively. At tailbud stage, three other keratins (62, 58 and 54Kd) began to express and could be detected by AF5. MAbs D10 and K12 gave different results, both of them could identify four keratinlike molecules with unusual molecular weights ( $\mathrm{Mr} 98,95$, 30 and $27 \mathrm{Kd}$ ). Moreover, D10 could also detect a $54 \mathrm{Kd}$ keratin in neurula and tailbud stage embryos, while K12 could reveal, beside $54 \mathrm{Kd}$ keratin, other four more keratins $(68,65,62$ and $60 \mathrm{Kd})$. The possible interpretation of these results and their implications are discussed.
\end{abstract}

Key Words: Keratin, immunoblotting or Western 6lctting, Bufo bufo gargarizans, early embryonic deveCopment.

\section{INTRODUCTION}

Expression of specific subclasses of intermediate filaments is currently considered as one of the best indicators of tissue differentiation and a good marker of embryonic development, although it is not fully understood why this diversity is required or what role it plays in cell and tissue physiology [1, 2]. Keratin (or cytokeratin) is an epithelial-specific intermediate filament protein. It constitutes the dominant class (or classes) of intermediate filaments from early embryogenesis onwards, even oocytes contain the keratin $[3,4]$. So far, 30 different polypeptides of keratin have been identified, with molecular weights covering the range of $40-70 \mathrm{Kd}$ [5]. Specific subsets of different keratin polypeptides are expressed in different epithelia, depending on their origin, stage of development or type of 
Keratin expression in early embryo of Bufo bufo gargarizans

differentiation. To date, few studies have been carried out on the ontogeny of the embryonic expression of keratin polypeptides.

In mouse, cytokeratins are thought to be expressed before the primitive streak stage $[4,6,7,8]$. Then, they are replaced by vimentin in primary mesenchyme cells [9]. Expression of other intermediate filaments, namely desmin, GFAP and the neurofilament proteins, has been demonstrated to be a sign of definite commitment of embryonic cells to differentiate into muscle tissue, glial cells or neurons respectively [10]. Also, a $40 \mathrm{Kd}$ keratin is identified to have a property of stage-specific expression [11].

In Xenopus laevis, intermediate filaments have been found in oocytes and early embryos $[12,13,14]$. Godsave et al reported that cytokeratin-containing filaments appeared during early oogenesis, changed their distribution during oocyte differentiation and further changed in fertilized egg and early embryo stages [3]. Several keratin MAbs against Xenopus laevis were raised to detect keratins of the tadpole by Western blotting. Results gotten form these MAbs were slightly different [15]. Jonas et al prepare a cDNA library by selecting out RNA molecules present in Xenopus gastrula but not in the egg. They found that the expression of type I keratin gene DG81 is limited to pre-adult developmental stages. DG81 is the earliest activated tissue-specific marker reported so far in Xenopus laevis [16]. Recently, another keratin gene XenCK55(5/6) of type II was identified to be transcribed first at St. 11 of Xenopus Caevis [17]. In Xenopus oocytes and early embryos, there existed 3 keratins with $\mathrm{Mr}$ of 42,46 and $56 \mathrm{Kd}[12]$.

Keratin is both an epithelial-specific protein and an important cytoskeletal ingredient $[2,5]$. In this paper, we choose Bufo bufo gargarizans as material to study keratin expression during early development of embryo. The results will provide some evidence that how keratin behaved in the early embryos of $B u f_{0}$ bufo gargarizans, which is very important for further research of keratin function in embryonic development and cell differentiation.

\section{MATERIALS AND METHODS}

\section{Animal}

Adult specimens of toad (Bufo bufo gargarizans) wore collected from Beijing northern suburbs.

\section{Embryos}

Female toads were injected with pituitary bodies. One day later, artificial insemination was performed and embryos of various stages of development were stored at $-20^{\circ} \mathrm{C}$ for use. Developmental stages were identified according to Mathews [18]. The experiments were repeated for three times.

\section{Extraction cf Cytoskeletal Proteins}

Cytoskeletal proteins from embryos and epithelial cells were prepared according to Reeves [19], Epidermis was separated from derma by immerging the skin overnight in $\mathrm{CMFB}(88 \mathrm{~m} M \mathrm{NaCl}, 24 \mathrm{~m} M$ $\mathrm{NaHCO}_{3}, 15 \mathrm{~m} M$ Tris, $\mathrm{pH}$ 7.8) containing $3 \mathrm{~m} M$ EDTA with continuous stirring. Epidermis or embryos were homogenized, extracted twice with $0.1 \mathrm{M}$ PBS ( $\mathrm{pH} 7.4$ )and then centrifugated $\left(20,000 \mathrm{~g}, 30 \mathrm{mins}, 4^{\circ} \mathrm{C}\right)$. Pellets 
were extracted with ethanol and ether, each for several times. The pellet was further dissolved in the solution of $0.1 M$ sulfhydrylethanol, $0.1 M$ ethanolamine, $8 M$ urea by $24 \mathrm{hrs}$ stirring, then centrifugated as above. The supernatant was stored at $-20^{\circ} \mathrm{C}$. Control experiments were done using supernatants from embryo bomogenate prepared by a solution of $3 \%$ SDS and 5\% sulfhydrylethanol in PBS.

\section{SDS-PAGE}

SDS-PAGE (Sodium Dodecyl Sulfate-Polyacrylamide Gel Electrophoresis) was performed as described by Laemmli [20]. The concentration of separating gel is $7.5 \%$.

\section{Immunoblotting (or Western blotting)}

Immunoblotting was done according to Towbin [21]. The first antibodies used were mice anti-human keratin MAb K12 (kindly provided by National Vaccine and Serum Institute, Beijing), mice anti-human keratin MAb AF5[22, kindly provided by Prof. Fan Weike] and mice anti-Xenopus keratin MAb D10 (prepared in our Lab). Alkaline phosphatase labelled rabbit anti-mouse IgG (from BIO-RAD Co. ) served as the second antibody.

\section{RESULTS}

Electrophoretic separation of the cytoskeletal protein preparation obtained from embryos and from epidermis of Bufo bufo gargarizans was done to determine the $\mathrm{Mr}$ of cytoskeletal proteins. Protein bands were different among various embryonic stages. In addition, some trace ingredients were not shown well due to less sensitivity of SDS-PAGE technique. In order to detect keratins specifically, the technique of immunoblotting was employed. By comparing SDS-PAGE with immunoblotting, we can get clearly the $\mathrm{Mr}$ of expressed keratins in early Bufo embryo. Three anti-keratin MAbs were used in our study, namely AF5, K12 and D10.

First, we used AF5 which has been well characterized with mammalian tissues, especially human tissues, reacting specifically with epidermis, except for basal cells, to detect keratins. The staining pattern by this antibody is shown in Fig. 1 and Table 1, from which we see that:

1. Oocytes contain keratins of 60,65 and $68 \mathrm{Kd}$, i. e., same as those of blastula, gastrula and neurula.

2. At tailbud stage, three additional types of keratins are expressed (54, 58 and $62 \mathrm{Kd}$ ).

3. The adult epidermis contains 7 kinds of keratins, which are not the same as the tailbud stage embryo's.

In our study, we prepared Xenopus MAb D10, which can specifically identify keratins (Fig. 2). It was revealed that all keratins in Hela cells can be recognized by D10 (Yu et al, unpublished observations). Using D10, we identified a $54 \mathrm{Kd}$ keratin, which was first detected in neurula. Four keratins-like molecules with unusual molecular weight of $98,95,30$ and $27 \mathrm{Kd}$ were also identified in all stages of the early embryos. But, none of them appeared in adult epidermis. To eliminate the possibility of keratin polymerization and breakage by high concentration of urea, we did control experiments using embryo homogenates made by a solution of $3 \%$ SDS and 5\% sulfhydrylethanol. The result was the 
Keratin expression in early embryo of Bufo bufo gargarizans

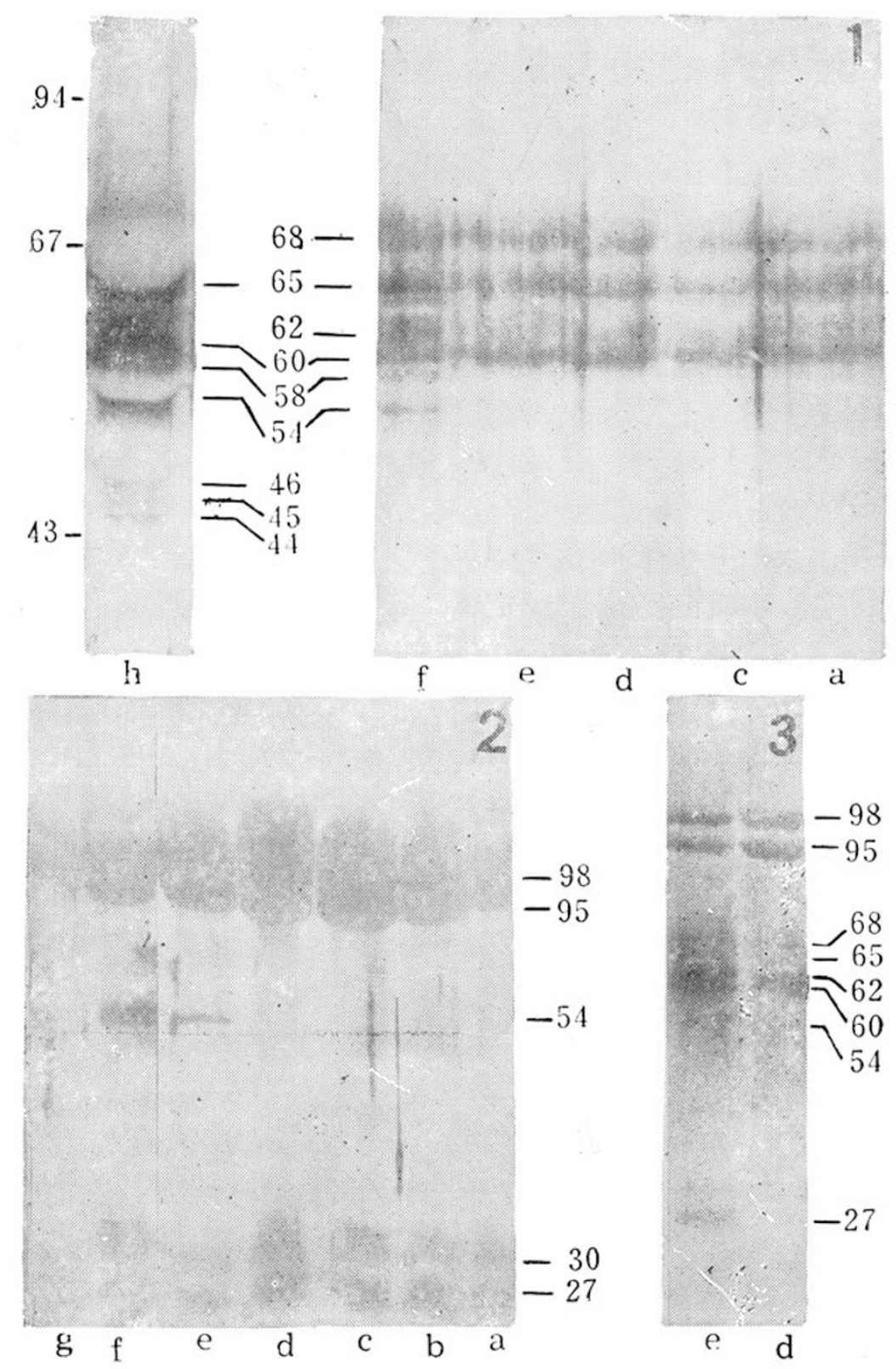

Keratin expression pattern in the early embryo of Bufo bufo gargarizans

Fig. 1. Immunoblotting pattern of keratins made by MAb AF5

Fig. 2. Immunoblotting pattern of keratins made by MAb D10

Fig. 3. Immunoblotting pattern of keratins made by MAb El2

a. oocyte; b. fertilized egg; c. blastula; d. gastrula; e. neuruIa; f. tailbud stage; g. ST. 22 embryo (tail fin circulation); h. adult epidermis. The Mr markers shown are: actin, 43Kd; albumin, $67 \mathrm{Kd}$; phosphorylase b, 94Kd. 
Xie JW and HJ Yu.

Table 1. Keratin expression in early embryos of Bufo Gufo gargarizans

\begin{tabular}{|c|c|c|c|c|c|c|c|c|c|c|c|c|c|}
\hline \multirow{2}{*}{$\begin{array}{l}\text { Stage } \\
\text { MAbs }\end{array}$} & \multicolumn{3}{|c|}{$\begin{array}{l}\text { Oocyte Fer-tilized } \\
\text { egg Blastula }\end{array}$} & \multicolumn{3}{|c|}{ Gastrula } & \multicolumn{3}{|c|}{ Neurula } & \multicolumn{3}{|c|}{$\begin{array}{l}\text { Tailbud } \\
\text { stage }\end{array}$} & \multirow{2}{*}{$\begin{array}{c}\begin{array}{c}\text { Adult } \\
\text { epidermis }\end{array} \\
\text { AF5 }\end{array}$} \\
\hline & AF5 & D10 & $\mathrm{K} 12$ & AF5 & D10 & K12 & AF5 & D10 & K12 & AF5 & D10 & $\mathrm{K} 12$ & \\
\hline & & 98 & 98 & & 98 & 98 & & 98 & 98 & & 98 & 98 & \\
\hline & & 95 & 95 & & 95 & 95 & & 95 & 95 & & 95 & 95 & \\
\hline Keratin & 68 & & 68 & 68 & & 68 & 68 & & 68 & 68 & & 68 & \\
\hline \multirow{10}{*}{$\begin{array}{c}\text { Pattern } \\
\text { (Kd) }\end{array}$} & 65 & & 65 & 65 & & 65 & 65 & & 65 & 65 & & 65 & 65 \\
\hline & & & & & & 62 & & & 62 & 62 & & 62 & \\
\hline & 60 & & 60 & 60 & & 60 & 60 & & 60 & 60 & & 60 & 60 \\
\hline & & & & & & & & & & 58 & & & 58 \\
\hline & & & & & & 54 & & 54 & 54 & 54 & 54 & 54 & 54 \\
\hline & & & & & & & & & & & & & 46 \\
\hline & & & & & & & & & & & & & 45 \\
\hline & & & & & & & & & & & & & 44 \\
\hline & & 30 & 30 & & 30 & & & 30 & & & 30 & 30 & \\
\hline & & 27 & 27 & & 27 & & & 27 & 27 & & 27 & 27 & \\
\hline
\end{tabular}

same as that shown in Fig. 2.

We have also detected keratins of toad embryos using mice antihuman keratin MAb K12. The results were summarized in Table 1. Fig. 3 represented the keratin staining pattern of gastrula and neurula, with 5 distinct polypeptide bands of $\mathrm{Mr} 54,60,62,65$, and $68 \mathrm{Kd}$, and four unusual keratin-like molecules (98, 95, 30 and $27 \mathrm{Kd}$ ) (30 Kd band is not so clear, possibly due to low content). The pattern was similar to that obtained by AF5 in tailbub stage, except for unusural keratins which were also identified by MAb D10 (Fig. 2, Table 1).

\section{DISCUSSION}

Our results obtained both by MAbs K12 and D10 show that four unusual keratins are among the earliest expressed keratins of Bufo embryo. The control experiment, using supernatant from embryo homogenates prepared by a solution of $3 \%$ SDS and 5\% sulfhydrylethanol, also leads to the same result. So, the possibility of keratin polymerization and degradation by high concentration of urea during keratin extraction is eliminated. Even though, whether SDS and sulfhydrylethanol (both of them existed in extraction buffer) do break down keratin proteins during the manipulation of immunoblotting is unknown. However, no keratins with molecular weight outside the range of $40-70 \mathrm{Kd}$ have been reported by previous workers when extraction was carried out using SDS and sulfhydrylethanol [19, 23]. Therefore, whether these high and low molecular weight keratinlike molecules in Bufo represent the complexes of keratins and its binding proteins or ever aggregates of differenb isoforms of acidic and basle keratins, or represent the degredation products remain to be studied [24]. 
Keratin expression in early embryo of Bufo bufo gargarizans

As regards to the different keratin pattern during the development, we have demonstrated immunohistochemically with MAb AF5 that keratin filaments exist in Bufo oocytes and fertilized eggs (Xie and Yu, unpublished observations). Results in this paper revealed the existence of keratins and keratin-like molecules (98, 95, 30 and $27 \mathrm{Kd}$ by MAb D10; 68, 65 and $60 \mathrm{Kd}$ by MAb AF5 and all these 7 by MAb K12) in oocytes and early embryos. We supposed that keratin filaments, in Bufo early embryos may be composed of keratins already existed in oocytes 68, 65, and $60 \mathrm{Kd}$ ), and largely of 98, 95, 30 and $27 \mathrm{Kd}$ keratin-like molecules. During the development of embryo, other keratins are gradually expressed and assembled into keratin filaments.

Comparing keratins of Bufo adult epidermis with that of early embryo (see Table 1), we find that some keratins of adult epidermis, like 65 and $60 \mathrm{Kd}$ keratins, already existed in oocytes, while others came into being one by one during development. $54 \mathrm{Kd}$ keratin was first detected in gastrula (Fig 3), and 58 Kd keratin began to express in tailbud embryo (Fig 1). Using AF5, we can not identify $68 \mathrm{Kd}$ molecule in adult epidermis, while in embryo, we could. We think further work is needed to confirm the property of $68 \mathrm{Kd}$ keratin. According to the principle of keratin filament assembly, keratins should come into being in pairs during embryonic development [5]. As shown above, most keratins of Bufo embryo appeared singly during early embryonic development. Study on keratin expression of mouse embryo also revealed that most kertins come into being one by one [6]. But, during mammalian epidermal differentiation, keratins emerge mostly in pairs [24]. From this point, we can see that further study on keratin expression in amphibian embryo is deemed necessary in order to clarify the mechanism of filament assembly in early embryonic development. We have identified several soluble keratins in early embryo and tadpole epidermis by immunoblotting (Xie and Yu, unpublished observations). May be, the early expressed keratin exists as soluble ingredients before the filament is formed. Morever, studies on epidermis differentiation lead to the conclusion that larger keratins are abundant only in differentiating epidermal cells, smaller keratins are present in many simple epithelia. From human epidermis, the commitment of basal cells to terminal differentiation and stratum cornea formation seems to be correlated with increased synthesis of larger keratins in 63-70 $\mathrm{Kd}$ range [24, 25]. In our study, however, larger keratins( $\mathrm{Mr} \mathrm{60,62,} 65$ and $68 \mathrm{Kd}$ ) appeared already in early Bufo embryos. The nature of such difference is not known.

Keratin expression during ear]y embryonic development of Bufo bufo gargarizans as revealed by MAbs AF5, D10 and K12 displayed some minor difference. AF5 debected $54 \mathrm{Kd}$ molecule first in tailbud stage, while $\mathrm{K} 12$ and D10 identified it first in gastrula and neurula stages respectively. This discrepancy cannot be correctly assessed at the moment, since $\mathrm{Hu}$ and Fan have shown that AF5 does stain keratinocytes, but not basal cells, of human epidermis [22], while we found that D10 and K12 can stain the whole epidermis. Further characterization of the epitope specificity of MAbs AF5, D10 and k12, and the preparation of more MAbs for Bufo keratins and the characterization of many 
Xie JW and HJ Yu.

keratin-like molecules from Bufo embryos are all needed before we can answer many questions arisen from this preliminary work.

\section{ACKNOWLEDGEMENT}

The project was supported by National Natural Science Foundation of China.

\section{REFFERENCES}

[ 1 ] Ferretti P, Fekete DM, Patterson M and Lane EB. Transient expression of simple epithelial keratins by mesenchymal cells of regenerating newt limb. Dev Biol 1989; 133:15-424.

[ 2 ] Osborn M and Weber K. Intermediate filaments: Cell-type-specific markers in differentiation and pathology. Cell 1982; 31: 303-306.

[ 3 ] Godsave SF, Wylie CC, Lane EB and Anderton BH. Intermediate filaments in the Xenopus oocyte: the appearence and distribution of cytokeratin-containing filaments. J Embry Exp Morph 1984: 83; 157167.

[ 4 ] Lehtonen E, Lehton VP, Vartio T, Badley RA and Virtanen I. Expression ofcytokeratin polypeptides in mouse oocytes and preimplantation embryos. Dev Biol 1983; 100:158-165.

[ 5 ] Shay JW. Cell and Molecular Biology of the Cytoskeleton. Plenum Press, New York. 1986; pp 85107.

[ 6 ] Jackson BW, Grund C, Schmid E, Eurki K, Franke WW and Illmensee K. Formation of cytoskeletal elements during mouse embryogenesis. I. Interme diate filaments of the cytokeratin type and desmosomes in preimplantation embryos. Differentiation. 1980; 17:161-179.

[ 7 ] Paulin D, Babinet C, Weber K and Osborn M. Antibodies as probes of cellular differentation and cytoskeletal organization in the mouse blastocyst. Expl Cell Res 1980; 130:297-304.

[ 8 ] Plancha CE, Carmo FM, and David FJ. Cytokeratin filaments are present in golden hamster oocytes and early embryos. Differentiation 1989; 42 (1): 1-9.

[ 9 ] Franke WW, Grund C, Kuhn C, Jackson BW and lllmensee K. Formation of cytoskeletal elements during mouse embryogenesis Ill. Primary mesenchymal cells and the first appearence of vimentin filaments. Differentiation 1982; 23: 43-59.

[10] Viebahn C, Lane EB and Ramaekers CS. Keratin and Vimentin expression in early organogenesis of the rabbit embryo. Cell Tiss Res 1988; 253: 553-562.

[11] Banks-Schlegel S. Keratin alterations during embryonic epidermal differentiation: A presage of adult epidermal maturation. J Cell Biol 1982; 93: 551-559.

[12] Franz JK, Gall L, Williams MA, Picheral B and Franke WW. Intermediate-size filaments in a germ cell: Expression of cytokeratins in oocytes and eggs of the frog Xenopus. Proc Natl Acad Sci 1983; 80: $6254-6258$.

[13] Gall L, Picheral B and Gounon P. Biochemical evidence for the presence of intermediate filaments and microfilaments in the egg of Xenopus laevis. Biol Cell 1983; 47: 331-342.

[14] Dent JA, Garlock and Klymskowsky MW. Expression and orgarnization of vimentin, cytokeratin and nuclear lamins during oogenesis and early developemnt in Xenopus laevis. J Cell Biol (suppl.) 1987; 105 (4) : pt2.285a

[15] Godsave SF, Anderton BH and Wylie CC. The appearance and distribution of intermediate filament proteins during differentiation of the central nervous system, skin and notochord of Xenopus Laevis. J Embryol exp Morph 1986; 97:201-233

[16] Jonas E, Sargent TD and Dawid 1B. Epidermal keratin gene expressed in embryos of Xenopus laevis. Proc Natl Acad Sci USA 1985; 82: 5143-5147.

[17] Fouquet B, Herrmann H, Franz JK and Franke WW. Expression of intermediate filament proteins during the development of Xenopus laevis. III. ldentification of mRNAs encoding cytokeratins typical of complex epithelia. Development 1988; 104: 533-548.

[18] Mathews WW. Atlas of Descriptive Embryology. Macmillam Publishing Co. lnc. (Third Edition). 1982; pp 31-34.

[19] Reeves OR. Adult amphibian epidermal proteins: Biochemical characterization and developmental appearance. J Embryol exp Morp 1975; 34: 55-92.

[20] Laemmli U. Cleavage of structural proteins during the assembly of the head of bacteriophage T4. Nature 1970; 227: 680-685. 
Keratin expression in early embryo of Bufo bufo gargarizans

[21] Towbin H, Staehelin T and Gordon J. Electrophoretic transfer of proteins from polyacrylamide gels to nitrocellulose sheets: Procedure and some applications. Proc Natl Acad Sci USA 1979; 76: 43504354 .

[22] Hu Jun and Fan Weike. Characterization of a hybridoma cell line and its antibody specificity. Ghinese J lmmuno] 1987; 3(5): 258-262.

[23] Sun TT, Shin CH and Green H. Keratin cytoskeleton in epithelial cells of internal organs. Proc Natl Acad Sci USA 1979; 76: 2813-2817.

[24] Sun TT, Tseng CG, Huang JW, Cooper D, Schermer A, Lynch MH, Weiss R and Elchner R. Monoclonal antibody studies of mammalian epithelial keratins: A review. Ann New York Acad Sci 1985; 455: 307-329.

[25] Ellison TR, Mathisen PM and Miller L. Developmental changes in keratin patterns during epidermal maturation. Dev Biol 1985; 112: 329-337.

Received 10-12-1990. Revised 6-2-1991. Accepted 24-2-1991. 